\title{
Long-term continuous erector spinae plane block for palliative pain control in a patient with pleural mesothelioma
}

\author{
Julio Ramos, MD $\cdot$ Philip Peng, MBBS, FRCPC $\cdot$ Mauricio Forero, MD, FIPP
}

Received: 26 January 2018/Revised: 17 February 2018/ Accepted: 18 February 2018/Published online: 27 February 2018

(C) Canadian Anesthesiologists' Society 2018

\section{To the Editor,}

Pleural mesothelioma is the most common type of asbestos-related cancer and has a median survival from presentation of nine to 12 months. ${ }^{1}$ The most common symptoms are dyspnea and chest pain. The pain arises from three sources: localized somatic pain from invasion of the chest wall, neuropathic pain from intercostal nerve or spinal canal invasion, and diffuse visceral pain from visceral pleura invasion. ${ }^{1,2}$

The erector spinae plane (ESP) block is a relatively new interfascial plane block originally described for thoracic neuropathic pain, ${ }^{3,4}$ but with an expanding number of reports in numerous other perioperative and pain settings. ${ }^{5}$ Thus far, however, no reports have outlined the use of the ESP block for the continuous delivery of local anesthetic in the management of pain from malignant mesothelioma in the outpatient setting.

Herein, we present a 57-yr-old female with a four-month history of malignant pleural mesothelioma. The main issue was severe chest wall pain radiating to the right shoulder refractory to conventional analgesia that included highdose parenteral opioids ( $80 \mathrm{mg} i v$ morphine per day). Thus, she was referred for an ESP block. An ultrasound-guided

J. Ramos, MD

Department of Anesthesia, Caja Petrolera de Salud, La Paz, Bolivia

P. Peng, MBBS, FRCPC

Department of Anesthesia and Pain Management, University of Toronto, Toronto, ON, Canada

M. Forero, MD, FIPP ( $\square)$

Department of Anesthesia, McMaster University, Hamilton, ON, Canada

e-mail: maoforeroman@hotmail.com diagnostic block was performed with the patient in the sitting position using a linear probe (GE LOGIQ e, Wauwatosa, WI, USA) $3 \mathrm{~cm}$ lateral to the spinous process at the $\mathrm{T} 3$ level in the paramedian sagittal plane under sterile technique. A 100-mm 21G needle (Stimuplex A, Braun Melsungen AG, Germany) was inserted in plane from cephalad to caudal direction to the plane between the erector spinae muscle and the transverse process of $\mathrm{T} 3$. Using hydrodissection to ensure optimal spread, a total of $20 \mathrm{~mL} 0.5 \%$ bupivacaine was administrated in divided doses. Thirty minutes following the block, the patient reported a decrease in chest wall and shoulder pain from 6 to 2 (numerical rating scale [NRS]; $0=$ no pain, $10=$ worst possible pain). She did not demand any rescue analgesic for that night and was able to sleep well.

Subsequently, an indwelling catheter was implanted targeting the T2 ESP level aiming to position the catheter tip at T3. After administration of $20 \mathrm{~mL}$ bupivacaine $0.5 \%$ using a single-shot needle (Figure A), an 18G 80-mm Tuohy needle (Braun, Melsungen AG) was introduced in the ESP followed by the insertion of a $20 \mathrm{G}$ catheter (Braun, Melsungen AG) $4 \mathrm{~cm}$ beyond the needle tip (Figure B, C). Intermittent boluses of $5 \mathrm{~mL}$ bupivacaine $0.5 \%$ were administered every eight hours for the first four days via the catheter. In addition, the intravenous parenteral dose of morphine was reduced from $80 \mathrm{mg} \cdot \mathrm{day}^{-1}$ to $50 \mathrm{mg} \cdot \mathrm{day}^{-1}$ without further need of rescue morphine. This regime allowed the patient to comfortably ambulate with a low resting pain score (NRS $=2 / 10)$. The pinprick test showed sensory block from T3 to T9 of the right hemithorax. An attempt was made to switch to continuous infusion using an elastomeric pump with a maximum rate of $5 \mathrm{~mL} \cdot \mathrm{hr}^{-1}$ over three days; a solution of up to $0.2 \%$ bupivacaine failed to reproduce the same analgesic effect. Therefore, intermittent bolus delivery was restored with $10 \mathrm{~mL}$ 



Figrue (A) An erector spinae plane block is performed using an inplane needle insertion from cephalad to caudal. The tip of the needle is located underneath the anterior aponeurotic fascia of the erector spinae muscle at the level of the T2 transverse process (TP2). Reprinted with permission from the Philip Peng Educational Series. (B) The catheter is inserted through an 18G Tuohy needle and is

bupivacaine $0.25 \%$ every eight hours administered by the patient's husband. This change resulted in adequate pain control, a decrease morphine infusion from 50 to 40 $\mathrm{mg} \cdot \mathrm{day}^{-1}$, and no rescue morphine. The patient remained with the catheter in place without adverse events until she finally succumbed to continued disease progression 66 days later.

In summary, we report the use of continuous ESP delivery through the insertion of a catheter that provided uneventful, long-term optimal analgesic delivery and improvement of quality of life in a patient with chest pain due to advanced mesothelioma. Further study is required to examine the effectiveness and safety of the continuous block in the outpatient setting.

Conflicts of interest None declared.

Editorial responsibility This submission was handled by Dr. Hilary P. Grocott, Editor-in-Chief, Canadian Journal of Anesthesia. clearly visualized in the erector spinae plane. (C) The tip of the Tuohy needle is visualized at the T2 transverse process (TP2), and the catheter is clearly seen in the erector spinae plane following the trajectory from the T2 to the T3 transverse process (TP3). Reprint with permission from Philip Peng Educational Series

Funding None.

\section{References}

1. Robinson BW, Musk AW, Lake RA. Malignant mesothelioma. Lancet 2005; 366: 397-408.

2. Hochberg $U$, Elgueta $M F$, Perez J. Interventional analgesic management of lung cancer pain. Front Oncol 2017; 7: 17.

3. Forero M, Adhikary SD, Lopez H, Tsui C, Chin KJ. The erector spinae plane block: a novel analgesic technique in thoracic neuropathic pain. Reg Anesth Pain Med 2016; 41: 621-7.

4. Muñoz F, Cubillos J, Bonilla AJ, Chin KJ. Erector spinae plane block for postoperative analgesia in pediatric oncological thoracic surgery. Can J Anesth 2017; 64: 880-2.

5. Forero M, Rajarathinam M, Adhikary SD, Chin KJ. Erector spinae plane block for the management of chronic shoulder pain: a case report. Can J Anesth 2018; 65: 288-93. 